удК 340.12

Т. Ч. Шаракшинова

Казанский (Приволжский) федеральный университет, 2. Казань, Российская Федерация

\title{
ПРОБЛЕМА КОРРУПЦИИ \\ В СВЕТЕ ОСНОВНЫХ ТИПОВ ПРАВОПОНИМАНИЯ
}

\begin{abstract}
АНнотАция. В статье отмечается мультидисциплинарный характер коррупции как научной проблемы, указывается на пробел в изучении коррупции на уровне общей теории права и государства. Автор рассматривает перспективы формулирования общетеоретического правового подхода к коррупции с позиций различных типов правопонимания. Анализируются преимущества и недостатки социолого-правового подхода к правопониманию в контексте общегуманитарного научного дискурса. Указывается на особую специфику философско-правового подхода к праву в изучении коррупции в естественно-правовом и либертарном варианте. Критикуются узкоотраслевые юридические рамки позитивистского подхода. На основании инструментальной теории права, предлагаемой С. С. Алексеевым, делается вывод о возможности преодоления узкопозитивистского подхода путем установления связей коррупции с иными правовыми явлениями, высказывается предположение о возможности интеграции преимуществ всех классических типов правопонимания на базе инструментальной теории права.

кЛЮЧЕВЫЕ СЛОВА. Коррупция; правопонимание; типы правопонимания; подходы к коррупции; инструментальная теория права; С. С. Алексеев.

ИНФОРМАЦИЯ О СТАТЬЕ. Дата поступления 23 июля 2017 г.; дата принятия к печати 11 октября 2017 г.; дата онлайн-размещения 25 октября 2017 г.
\end{abstract}

T. Ch. Sharakshinova Kazan Federal University, Kazan, Russian Federation

\section{PROBLEM OF CORRUPTION IN TERMS OF MAIN TYPES OF LEGAL CONSCIOUSNESS}

\begin{abstract}
The article notes the multidisciplinary character of corruption as a scientific problem, indicates a gap in studying corruption at the level of the general theory of state and law. The author considers the prospects of formulating a general theoretical legal approach to corruption from the standpoint of different types of legal consciousness. The article analyses advantages and disadvantages of the socio-legal approach to legal consciousness in the context of general humanitarian scientific discourse. It points out to a specific function of the philosophical and legal approach to the law in studying corruption in the natural-legal and libertarian variant. It criticize the narrow legal frameworks of the positivist approach. On the ground of the instrumental theory of law proposed by S.S. Alekseyev, a conclusion is made about a possibility of integrating the advantages of all classical types of legal consciousness on the basis of the instrumental theory of law.

KEYWORDS. Corruption; legal consciousness; types of legal consciousness; approaches to corruption; instrumental theory of law; S. S. Alekseyev.

ARTICLE INFO. Received July 23, 2017; accepted October 11, 2017; available online October 25, 2017.
\end{abstract}

Отмечается, что проблематика коррупции в последнее десятилетие получила достаточно обширное научное освещение в самой разной литературе: социологической, экономической, политологической, правовой [1, с. 59]. Такая востребованность вполне оправдывается актуальностью и междисциплинарным характером проблемы. Однако подобный плюрализм подходов порождает доктринальные пробелы, которые

(C) T. Ч. Шаракшинова, 2017

\section{Baikal Research Journal}

электронный научный журнал Байкальского государственного университета 
легко увидеть из многочисленных обзоров доктринальных и легальных определений коррупции [см. $2 ; 3 ; 4]$. Не вдваваясь в частности и рассматривая определения коррупции через структуру научного знания, можно заметить неравномерное внимание, которое различные научные дисциплины уделяют изучению коррупции.

Общеизвестным считается, что наиболее фундаментальной юридической дисциплиной является теория государства и права, которая играет роль фильтра между юридическими и иными гуманитарными науками. С науковедческой точки зрения логичным было бы предположить, что в рамках теории государства и права должны сталкиваться и синтезироваться две тенденции в изучении коррупции: подход, сформировавшийся в рамках общегуманитарного дискурса на основе социологических, экономических и философских взглядов, с одной стороны, и выработанный в рамках отраслевых правовых дисциплин, в первую очередь, административного права и наук уголовно-правового цикла, с другой. Столкновение двух этих тенденций на основании развитого общетеоретического правового категориального аппарата является важнейшей предпосылкой к формулированию подхода к коррупции как государственно-правовому явлению, и разработки общих правовых основ противодействия ей. Однако как показывает анализ общетеоретических диссертаций, посвященных интересующей нас проблеме, понятие коррупции по-прежнему заимствуется или из общегуманитарных $[5$, с. 7 ; 6 , c. 10-11], или из отраслевых юридических дисциплин $[7$, с. 9-10; 8, с. 11] без теоретической рефлексии. Методологически такая постановка проблемы ведет к невозможности для исследователя осознанно определить собственный предмет исследования в объекте, что может привести к дефектам результата исследования,

Поражая сферу деятельности исполнительной власти, нарушая нормальный ход применения права, вызывая в качестве реакции определенные меры государственного принуждения, коррупция все еще представляет собой понятие, сконструированное политологами, социологами и экономистами и некритически воспринятое правоведами.

Решением обозначенной проблемы может стать выработка общетеоретического правового подхода к коррупции с использованием познавательного инструментария, сформировавшегося в рамках теории государства и права. Отправным пунктом, по нашему мнению, должен являться анализ эвристических возможностей различных типов правопонимания в отношении коррупции. Постановка проблемы осложняется давней теоретической дискуссией о типах правопонимания, их количестве и критериях выделения [подробнее см.: 9, с. 32-43; 10, с. 47-64; 11, с. 23-25]. Не вступая в нее по существу, считаем возможным выделить три классических типа правопонимания: философский (естественно-правовой), позитивистский и социологический (иные классификации, например, предлагаемое Н. А. Пьяновым деление типов правопонимания на нравственный, нормативный и социологический вполне соотносятся с нашим подходом [12, с. 112]). Следует согласиться с И. Л. Честновым, полагающим, что эти традиционные типы правопонимания не в полной мере отвечают вызовам постмодерна, и нужно либо отыскать в них дополнительный познавательный потенциал, либо интегрировать их, либо сформировать новые типы правопонимания, например, на основе правовой антропологии, экономического анализа права, синергетики, герменевтики [13, с. 554-555]. Не ставя целью охватить в данной статье все возможные новые теории, позиционирующие себя в качестве основ актуального правопонимания, считаем правильным сконцентрироваться в данной статье на познавательных потенциях, заложенных в традиционных типах правопонимания.

Представляется, что наиболее востребованным в современном дискурсе противодействия коррупции является социологическое направление правопонимания.

\section{Baikal Research Journal}

электронный научный журнал Байкальского государственного университета 
Не случайно коллектив авторов монографии под редакцией Т. Я. Хабриевой склонен рассматривать коррупцию именно как социальное явление [14, с. 17]. Распространенным стало использование в юридических исследованиях результатов социологических опросов. Так, широко известный рейтинг восприятия коррупции, формируемый международной организацией «Трансперенси Интернешнл», часто используется для обоснования актуальности темы исследования [например, 7 , с. $3 ; 8$, с. $4 ; 14$, с. 13]. Часто коррупция воспринимается в контексте иных социальных процессов, как фактор, влияющий на их возникновение, развитие и характер [см., например: 15 , с. $86 ; 16$, с. 167].

С одной стороны, нельзя не приветствовать желание осмыслить коррупцию в качественно-количественных показателях, выяснить причины ее возникновения и связи с иными социальными явлениями. Однако социолого-правовую природу коррупции такие исследования раскрывают слабо, освещая лишь социологическую сторону вопроса. Как видится нам, одной из наиболее характерных черт коррупции является ее устойчивость, своеобразная социальная нормативность, отличная, тем не менее, от нормативности позитивного права, но имеющая с ней общие черты. Нельзя не видеть, что коррупционные отношения возникают на основе своеобразного соглашения: как между чиновником и взяткодателем, так и в целом конвенционального признания обществом допустимости определенного уровня коррупции в определенных сферах. Нетрудно увидеть, что социологическое правопонимание в отношении коррупции имеет связи как с социологией (а через нее - с экономикой и политологией), так и с криминологией, что является предпосылкой для интеграции разных подходов на юридической основе, но повышает риск необоснованного размытия междисциплинарных границ.

В свете изложенного выше, социологическое правопонимание, расширяющее границы права до того, что ощущается и действует как право в данном обществе, имеет потенциал в плане выяснения дальнейшей социо-нормативной природы коррупции, ее основ в смежных с позитивным правом регуляторах, в характере социальных коммуникаций. Положительные примеры такого подхода встречаются в исследованиях, определяющих коррупцию, например, через категорию неправомерного поведения [17, с. 19], правового нигилизма и деформации правосознания $[18$, с. 10$]$, что открывает возможности использования социолого-правовых методов в изучении коррупции.

Остается во многом дискуссионным вопрос о познавательных способностях философского (естественно-правового) типа правопонимания и примыкающей к нему, на наш взгляд, либертарной теории права. Обнажая свою философскую сущность, данный подход с большим трудом может быть интерпретирован в практических категориях, одной из которых как раз и является сфера противодействия коррупции. Ставя во главу угла индивидуальную свободу и права человека, сторонники данного подхода, с одной стороны, отказываются от пафоса публичного интереса, а с другой - делают шаг от науки в сторону идеологии [19, с. 50]. Соответственно, в идеологических проектах сторонников философско-правового типа понимания априори заложена невозможность и недопустимость существования коррупции. Вероятно, такие меры, как построение государственного аппарата на основах минимального вмешательства в дела гражданского общества, повышение степени саморегулируемости вкупе с более строгим контролем за публичной администрацией могут приветствоваться прежде всего с позиций естественно-правового типа правопонимания.

На наш взгляд, коррупция с либертарных позиций может быть рассмотрена через категорию формального равенства [20, с. 223]. Действительно, реализация при помощи государства неправомерных интересов [21, с. 226], в чем как раз

\section{Baikal Research Journal}

электронный научный журнал Байкальского государственного университета 
и выражается коррупция, представляет собой произвольные изменения равной меры свободы, своеобразный дефект в основанной на принципе формального равенства деятельности государства, мыслимого не иначе как институциональная форма защиты свободы [13, с. 563]. Данный подход оставляет возможность для практической антикоррупционной деятельности в реальной действительности, поскольку мера свободы в отличие от естественных прав является категорией, прочнее связанной с социальной конъюнктурой.

Что касается традиционно позитивистских интерпретаций коррупции, то это направление также является достаточно распространенным в отечественной правовой литературе, причем чаще всего в своих крайних, легистских проявлениях. Легистские воззрения сводятся $\kappa$ безоговорочному восприятию легального определения, содержащегося в федеральном законе от 25 декабря 2008 года № 273-Ф3 «O противодействии коррупции» ${ }^{1}$, либо в акцентировании внимания на легальных дефинициях так называемых «правонарушений коррупционной направленности», что иногда подвергается критике [22, с. 5-6]. На более высоком уровне теории такие определения коррупции могут быть сведены к нормативизму: коррупция мыслится как нарушение позитивно-правовой нормы, содержащей запрет, то есть как юридически значимое деяние, юридический факт, запускающий механизм государственного принуждения в отношении нарушителя.

Таким образом, по своему генезису позитивистские подходы к коррупции стремятся к отраслевым определениям, сформулированным в рамках административного и уголовного права. С одной стороны, это дает тесную связь с юридической практикой, а в случае с административно-правовым подходом - возможность интеграции с политологическим дискурсом. С другой - суживает постановку проблемы коррупции до юридического отраслевого или межотраслевого уровня.

Признавая известные положительные стороны данного подхода, считаем целесообразным высказать по этому вопросу несколько замечаний. Проблема коррупции относится в числе прочего не просто к социальным, но и к собственно правовым проблемам, поскольку тесно связана с рядом правовых категорий самого различного уровня. С. С. Алексеев, формулируя положения инструментальной теории права как некоего научного образования высокого порядка, выводимого из аналитической юриспруденции, отмечал, что при изучении права наряду с нормами должны рассматриваться иные правовые средства и явления [23, с. 76].

Соглашаясь с С. С. Алексеевым, мы полагаем перспективным направлением исследований в области противодействия коррупции установление функциональных и системных связей между коррупцией как особым явлением, оказывающим своеобразное влияние на правовую материю, и элементами этой материи. В полном объеме исследовательский потенциал этой концепции только предстоит оценить, однако возможны следующие предварительные замечания. Открытие правовых общностей частного и публичного права как направлений развития правового регулирования позволяет говорить о необходимости обеспечения гармоничного их развития [23, c. 126]. Также С. С. Алексеев обращает внимание на историческую диалектику борьбы права с политическим произволом [23, с. 150]. С точки зрения периодизации права он выделяет такие ступени права, как право сильного, право власти, право государства и право гражданского общества, последовательно отличающиеся степенью реализации социальной роли права в жизни общества [23, с. 166-176].

На наш взгляд, коррупция представляет собой изначально политическое явление. В период права сильного и права власти она воспринималась как определенная совокупность преступлений против порядка управления, угрожавших в

${ }^{1}$ О противодействии коррупции : федер. закон от 25 дек. 2008 г. № 273-ФЗ : (в ред. федер. закона от 15 февр. 2016 г.) // Собр. законодательства РФ. 2008. № 52 (Ч. 1). Ст. 6228 ; 2016. № 7. Ст. 912.

\section{Baikal Research Journal}

электронный научный журнал Байкальского государственного университета 
первую очередь доминирующему политическому суверену, нежели правовой стабильности. Однако с ростом социальной значимости права она получила значение правового явления, стала особым, ненормальным режимом функционирования правовых институтов. С усложнением структуры правовой материи, ростом степени урегулированности общественных отношений позитивным правом, количества правовых ситуаций применение силы в чистом виде уступило место правовым имитациям, инициатива которых может исходить не только от властных структур, но и от заинтересованных субъектов права. Можно считать, что само понятие коррупции, сформулированное гуманитарным дискурсом на определенном историческом этапе, качественно отличается от исходного перечня коррупционных правонарушений, и описывает соответствующую деформацию правовой сферы, претендуя на известный уровень абстракции.

Нетрудно увидеть, что одна из центральных категорий инструментальной теории права, механизм правового регулирования, под воздействием коррупции приобретает аномальные черты. Привнося в публично-правовую сферу, и без того тесно связанную с властью, а значит, и с возможностью произвола, идею личной выгоды, автономии воли чиновника и взяточника, специфичный квазидоговорный характер взаимоотношений между участниками коррупционной схемы (свойственные частному праву), коррупция меняет нормальные функциональные связи правовой материи, решает жизненные ситуации на основе видимости права, лишая право критериев определенности, всеобщей обязательной нормативности. В условиях распространенности коррупции существует угроза того, что любой юридический факт, основанный на властном решении, может оказаться не результатом правоприменения, а фикцией, следовательно, правоотношение и иные связанные с ним юридические средства сработают таким образом, который противен их социальному назначению. Есть все основания считать коррупционные отношения особой формой произвола, характерной для двух наиболее развитых ступеней права, органически связанной с развитием права и в силу этого нуждающейся в правовом освещении, прежде всего, в рамках аналитической юриспруденции.

Подводя итог, следует согласиться с мнением А. А. Сизова относительно того, что системность как критерий коррупции продолжает оставаться неразрешенной научной проблемой [24, с. 56]. Каждая из отраслей гуманитарного и, более узко, юридического знания, объясняет системные связи коррупции по-своему, используя различную методологию. Социологические и примыкающие к нему подходы рассматривают коррупцию как определенное социальное явление, административное и уголовное право - как систему правонарушений, которая может быть объектом противодействия. Теоретико-правовой подход к коррупции, как нам думается, должен базироваться на учете различных типов правопонимания. Несмотря на попытки сформулировать новый тип правопонимания, основой научных исследований продолжают оставаться «классические» типы правопонимания ${ }^{2}$. Наиболее тесно в диалектическом единстве взаимодействуют социолого-правовое и позитивистское направления правопонимания, отвечающие различным

2 Что касается современных разработок нового типа правопонимания, то, безусловно, и они содержат известный потенциал в исследовании различных аспектов проблемы коррупции. Так, коммуникативно-феноменологический подход может рассматривать коррупцию как специфичную форму диалога. Нельзя не видеть возможности экономического анализа права, правовой антропологии в части рассмотрения коррупции как критерия рационального выбора и формы деятельности людей соответственно. Однако, на наш взгляд, эти новые подходы к пониманию права в настоящий момент находятся в стадии формирования своих собственных принципов, понятийно-категориального аппарата, методов познания, и борются за научное признание, стремясь отграничить себя от «классических», основных типов правопонимания, которые, как показывает практика научных исследований, продолжают оставаться вполне современными.

\section{Baikal Research Journal}

электронный научный журнал Байкальского государственного университета 
потребностям практики и по-разному способные систематизировать проблему коррупции. Дальнейшее движение в этом направлении может развиваться по пути их сближения друг с другом, поскольку данные социологии права оказываются востребованными в процессе правотворчества по вопросам противодействия коррупции, а позитивистские трактовки - в правоприменительной деятельности.

Вместе с тем, познавательные потенции позитивистского правопонимания относительно проблемы коррупции исчерпаны далеко не полностью. Понимаемая через призму категорий аналитической юриспруденции, поднимаясь на более высокий уровень абстракции по сравнению с отраслевыми юридическими формулировками, проблема коррупции приобретает системное звучание и содержит предпосылки для синтеза преимуществ всех трех основных типов правопонимания. Подлинно юридическая общетеоретическая системность коррупции должна базироваться не на включении коррупции в какую-либо одну категорию теории государства и права, пусть даже такую разработанную, как правонарушение, но на интерпретации ее как правового явления, что подразумевает установление ее системных связей с иными категориями аналитической юриспруденции. Отдельные элементы такого подхода можно видеть в соображениях Г. Алексеева и Г. Морозова, связывающих коррупцию с категориями правопорядка и законности, основываясь на их общетеоретическом разграничении [25, с. 135]. Подобного рода формулировки позволят связать проявления коррупции с ее социолого-правовым пониманием, поскольку характерные для последнего внимание к общественной опасности и особой нормативности коррупции подразумевает ее учет как фактора в правовой политике, которая видится возможной точкой пересечения всех юридических подходов к коррупции. Философский же тип правовопонимания, предъявляющий наиболее общие требования к принципам правового регулирования, совместим как с социологическим, так и позитивистским правопониманием.

\section{Список использованной литературы}

1. Андриянов В. Н. Некоторые современные проблемы противодействия коррупции в органах государственной власти / В.Н.Андриянов // Криминологический журнал БГУЭП. - 2013. - № 4. - С. 58-64.

2. Изотов М. О. Понятие коррупции: основные подходы / М. О. Изотов // Ученые записки Орловского государственного университета. Серия «Гуманитарные и социальные науки». - 2011. - № 6. - С. 133-138.

3. Заброда Д. Г. Коррупция: неправовые подходы к определению понятия / Д. Г. Заброда // Проблемы правоохранительной деятельности. — 2013. - № 2. - С. 131-137.

4. Хабриева Т. Я. Коррупция и право: доктринальные подходы к постановке проблемы / Т. Я. Хабриева // Журнал российского права. - 2012. - № 6. - С. 5-17.

5. Кузнецов А. Н. Преодоление коррупции в государственном аппарате (теоретико-правовой аспект) : автореф. дис. ... канд. юрид. наук : 12.00.01 / А. Н. Кузнецов. - СПб, 2000. $-18 \mathrm{c}$.

6. Чуманов А. В. Правовая политика в сфере противодействия коррупции в России (вопросы теории и истории) : автореф. дис. ... канд. юрид. наук : 12.00.01 / А. В. Чуманов. Волгоград, 2007. - 29 с.

7. Бирюков А. В. Антикоррупционная правовая политика России: история и современность : автореф. дис. ... канд. юрид. наук : 12.00.01 / А. В. Бирюков. - Краснодар, 2014. -25 c.

8. Александров С. Г. Правовой механизм борьбы полиции с коррупцией (сравнительно-правовое исследование на примере Российской Федерации и ведущих зарубежных стран) : автореф. дис. ... канд. юрид. наук : 12.00.01 / С. Г. Александров. - М., 2005. - 38 с.

9. Малахов В. П. Общая теория права и государства. $К$ проблеме правопонимания : учеб. пособие / В. П. Малахов. - М. : Юнити-Дана, 2013. - 144 с.

\section{Baikal Research Journal}


10. Оль П. А. Правопонимание: от плюрализма к двуединству / П. А. Оль. - СПб. : Юридический центр Пресс, 2005. - 243 с.

11. Сорокин В. В. Понятие и сущность права в духовной культуре России / В. В. Сорокин. - М. : Юрлитинформ, 2007. - 456 с.

12. Пьянов Н. А. Актуальные проблемы теории государстве и права / Н. А. Пьянов. 2-е изд., перераб. и доп. - Иркутск : Изд-во ИГУ, 2011. - 255 с.

13. Честнов И. Л. Постклассическая теория права / И. Л. Честнов. - СПб. : АлефПресс, 2012. - 650 с.

14. Коррупция: природа, проявления, противодействие : монография / отв. ред. Т. Я. Хабриева. - М. : Юриспруденция, 2012. - 688 с.

15. Ардельянова Я. Л. Теоретико-методологические подходы к понятию «коррупция» / Я. Л. Ардельянова // Идеи и идеалы. - 2013. - № 3. - С. 86-93.

16. Шинкевич В. Е. Коррупция как социально-правовое явление: исторический аспект и некоторые проблемы осмысления / В. Е. Шинкевич // Вестник Полоцкого государственного университета. Серия D, Экономические и юридические науки. - 2012. - № 14. - C. 162-168.

17. Костенников М. В. К вопросу о понятии коррупции в российском праве / М. В. Костенников // Вестник Всероссийского института повышения квалификации сотрудников МВД РФ. - 2010. - № 1. - С. 16-21.

18. Хорольский Г. В. Государственно-правовая антикоррупционная идеология в структуре российской правовой системы: теоретико-правовой анализ : автореф. дис. ... канд. юрид. наук : 12.00.01 / Г.В. Хорольский. - Волгоград, 2011. - 39 с.

19. Поляков А. В. Общая теория права : курс лекций / А. В. Поляков. - СПб. : Юридический центр Пресс, 2001. - 642 с.

20. Нечаев А. Н. Ценность права с позиции либертарно-юридической концепции правопонимания, разработанной академиком В.С. Нерсесянцем / А. Н. Нечаев // Вестник Тамбовского государственного университета. - 2011. - № 6. - С. 222-226.

21. Лапаева В. В. Типы правопонимания: правовая теория и практика / В. В. Лапаева. М. : Российская академия правосудия, 2012. - 579 с.

22. Кудашкин А. В. Еще раз о правовом понятии коррупции / А. В. Кудашкин, Т. Л. Козлов // Современное право. - 2010. - № 6. - С. 3-8.

23. Алексеев С. С. Собрание сочинений. В 10 т. Т. 6. Восхождение к праву. Поиски и решения / С. С. Алексеев. - М. : Статут, 2010. - 558 с.

24. Сизов А. А. К вопросу о понятии коррупции и критериях его определения в современной юриспруденции / А. А. Сизов // Актуальные проблемы социально-гуманитарного и научно-технического знания. - 2014. - № 1. - С. 55-56.

25. Алексеев Г. К вопросу об уточнении понятия «коррупция» в российском законодательстве / Г. Алексеев, Г. Морозов // Власть. - 2011. - № 5. - С. 134-136.

\section{References}

1. Andriyanov V. N. Some present-day problems of corruption counteraction in bodies of state power. Kriminologicheskii zhurnal Baikal'skogo gosudarstvennogo universiteta ekonomiki $i$ prava = Criminological Journal of Baikal State University of Economics and Law, 2013, no. 4, pp. 58-64. (In Russian).

2. Izotov M. O. Concept of corruption: main approaches. Uchenye zapiski Orlovskogo gosudarstvennogo universiteta. Seriya "Gumanitarnye $i$ sotsial'nye nauki» = Transactions of Orlov State University. Series «Humanitarian and Social Sciences», 2011, no. 6, pp. 133-138. (In Russian).

3. Zabroda D. G. Corruption: non-legal approaches to definition of the concept. Problemy pravookhranitel'noi deyatel'nosti = Problems of Law Enforcement Activities, 2013, no. 2, pp. 131-137. (In Russian).

4. Khabrieva T. Ya. Corruption and law: doctrinal approaches to statement of the question. Zhurnal rossiiskogo prava = Journal of Russian Law 2012, no. 6, pp. 5-17. (In Russian).

5. Kuznetsov A. N. Preodolenie korruptsii $v$ gosudarstvennom apparate (teoretiko-pravovoi aspekt). Avtoref. Kand. Diss. [Overriding corruption in governmental machine (theoretical and legal aspect). Cand. Diss. Thesis]. Saint Petersburg, 2000. 18 p.

\section{Baikal Research Journal}


6. Chumanov A. V. Pravovaya politika $v$ sfere protivodeistviya korruptsii $v$ Rossii (voprosy teorii $i$ istorii). Avtoref. Kand. Diss. [Legal policy in corruption counteraction sphere in Russia (issues of theory and history). Cand. Diss. Thesis]. Volgograd, 2007. 29 p.

7. Biryukov A. V. Antikorruptsionnaya pravovaya politika Rossii: istoriya i sovremennost'. Avtoref. Kand. Diss. [Russia's anticorruption legal policy: history and modern age. Cand. Diss. Thesis]. Krasnodar, 2014. 25 p.

8. Aleksandrov S. G. Pravovoi mekhanizm bor'by politsii s korruptsiei (sravnitel'no-pravovoe issledovanie na primere Rossiiskoi Federatsii $i$ vedushchikh zarubezhnykh stran). Avtoref. Kand. Diss. [Legal mechanism of police fight with corruption (comparative-legal investigation in terms of the Russian Federation and leading foreign countries). Cand. Diss. Thesis]. Moscow, 2005. 38 p.

9. Malakhov V. P. Obshchaya teoriya prava $i$ gosudarstva. $K$ probleme pravoponimaniya [General theory of state and law. On problem of legal consciousness]. Moscow, Yuniti-Dana Publ., 2013. 144 p.

10. Ol' P. A. Pravoponimanie: ot plyuralizma $k$ dvuedinstvu [Legal consciousness: from pluralism to duality]. Saint Petersburg, Yuridicheskii tsentr Press Publ., 2005. 243 p.

11. Sorokin V. V. Ponyatie i sushchnost' prava $v$ dukhovnoi kul'ture Rossii [Concept and essence of law in Russia's spiritual culture Moscow]. Moscow, Yurlitinform Publ., 2007. $456 \mathrm{p}$.

12. Pyanov N. A. Aktual'nye problemy teorii gosudarstve i prava [Topical problems of theory of state and law]. $2^{\text {nd }}$ ed. Irkutsk State University Publ., 2011. 255 p.

13. Chestnov I. L. Postklassicheskaya teoriya prava [Post-classical theory of law]. Saint Petersburg, Alef-Press Publ., 2012. 650 p.

14. Khabrieva T. Ya. (ed.). Korruptsiya: priroda, proyavleniya, protivodeistvie [Corruption: nature, manifestation, counteraction]. Moscow, Yurisprudentsiya Publ., 2012. 688 p.

15. Ardelyanova Ya. L. Theoretical and methodological approaches to notion "corruption». Idei $i$ idealy $=$ Ideas and Ideals, 2013, no. 3, pp. 86-93. (In Russian).

16. Shinkevich V. E. Corruption as a socio-legal phenomenon: historical aspect and some problems of comprehension. Vestnik Polotskogo gosudarstvennogo universiteta. Seriya D, Ekonomicheskie i yuridicheskie nauki = Bulletin of Polotsk State University. Series D. Economic and Juridical Sciences, 2012, no. 14, pp. 162-168. (In Russian).

17. Kostennikov M. On issue of concept of corruption in Russian law. Vestnik Vserossiiskogo instituta povysheniya kvalifikatsii sotrudnikov MVD RF = Bulletin of All-Russian Institute of Retraining RF Interior Ministry Members, 2010, no. 1, pp. 16-21. (In Russian).

18. Khorol'skii G. V. Gosudarstvenno-pravovaya antikorruptsionnaya ideologiya $v$ strukture rossiiskoi pravovoi sistemy: teoretiko-pravovoi analiz. Avtoref. Kand. Diss. [State-legal anticorruption ideology in structure of Russian legal system: theoretical and legal analysis. Cand. Diss. Thesis]. Volgograd, 2011. 39 p.

19. Polyakov A. V. Obshchaya teoriya prava [General theory of law]. Saint Petersburg, Yuridicheskii tsentr Press Publ., 2001. 642 p.

20. Nechaev A. N. Value of law in terms of libertarian-legal concept of legal consciousness worked out by academician V. S. Nersesyants. Vestnik Tambovskogo gosudarstvennogo universiteta $=$ Bulletin of Tambov State University, 2011, no. 6, pp. 222-226. (In Russian).

21. Lapaeva V. V. Tipy pravoponimaniya: pravovaya teoriya i praktika [Types of legal consciousness: legal theory and practice]. Moscow, Russian Academy of Justice Publ., 2012. 579 p.

22. Kudashkin A. V., Kozlov T. L. Once again about legal concept of corruption. Sovremennoe pravo $=$ Modern Law, 2010, no. 6, pp. 3-8. (In Russian).

23. Alekseev S. S. Sobranie sochinenii. V 10 t. T. 6. Voskhozhdenie k pravu. Poiski $i$ resheniya [Collection of Works. In $10 \mathrm{vol}$. Vol. 6. Ascent to Law. Pursuit and Solutions]. Moscow, Statut Publ., 2010. 558 p.

24. Sizov A. A. On issue of notion of corruption and criteria of its definition in modern jurisprudence. Aktual'nye problemy sotsial'no-gumanitarnogo $i$ nauchno-tekhnicheskogo znaniya = Topical problems of socio-humanitarian and scientific-technical knowledge, 2014, no. 1, pp. 55-56. (In Russian).

25. Alekseev G., Morozov G. On issue of specifying the notion "corruption» in Russian legislation. Vlast' $=$ Power, 2011, no. 5, pp. 134-136. (In Russian).

\section{Baikal Research Journal}




\section{Информация об авторе}

Шаракшинова Туяна Чингисовна - Аспирант, кафедра теории и истории государства и права, ФГАОУ ВО «Казанский (Приволжский) федеральный университет», 420008, Казань, ул. Кремлевская, 18, e-mail: tuyana.91@mail.ru.

\section{Author}

Tuyana Ch. Sharakshinova - PhD Student, Chair of The Theory and History of State and Law, Kazan Federal University, 18, Kremlyovskaya str., Kazan, 420008, e-mail: tuyana.91@ mail.ru.

\section{Для цитирования}

Шаракшинова Т. Ч. Проблема коррупции в свете основных типов правопонимания / Т. Ч. Шаракшинова // Baikal Research Journal. - 2017. - T. 8, № 3. - DOI : 10.17150/2411-6262.2017.8(3).25.

\section{For Citation}

Sharakshinova T. Ch.. Problem of corruption in terms of main types of legal consciousness. Baikal Research Journal, 2017, vol. 8, no. 3. DOI : 10.17150/2411-6262.2017.8(3).25. (In Russian).

\section{Baikal Research Journal}

